\title{
African Swine Fever Virus: Generation of Subpopulations with Altered Immunogenicity and Virulence Following Passage in Cell Cultures
}

\author{
I. C. Pan* \\ USDA, NAA, ARS, Plum Island Animal Disease Center, P. O. Box 848, Greenport, New York 11944, U.S.A.
}

(Received 24 July 1991/Accepted 11 October 1991) ABSTRACT. Virus subpopulations with variable virulence, immunogenicity, and infectivity to pigs were readily generated
by passaging Tengani isolate of African swine fever virus, either biologically cloned or uncloned, in Vero cell cultures.
Avirulent virus populations which account for more than $99 \%$ of virus in an uncloned preparation of the 27 th passage are
laboratory artefacts, perhaps do not exist in nature. Furthermore, attenuation of virulence did not occur uniformly in all
subpopulations newly generated, and a continuous modulation of virus populations differing in immunogenicity and
virulence took place in the same individuals inoculated with the 27 th passage virus. The same virus preparation,
appearing to be slightly virulent in pigs, contained at least a virulent subpopulation that was manifested only by further
inoculating susceptible pigs with viremic blood collected at various times during the clinical course. A cloned virus after
23 passages in cell cultures generated a subpopulation ( $99.9 \%$ ) which induced subclinical infection in pigs; however, the
infection did not confer a solid immunity to homologous challenge with Tengani isolate in these pigs. The Tengani isolate
contained subpopulations of virus with immunogenicities shared by the Lisbon ' 60 isolate and also contained at least one
subpopulation specific for the Tengani only.-KEY words: African swine fever virus, cytoplasmic DNA virus, modulation
of virus population, virulence and immunogenicity.

J. Vet. Med. Sci. 54(1): 43-52, 1992

African swine fever (ASF) is a dreadful malady of suidae, caused by a cytoplasmic DNA virus $[1,2,7$, $18,27]$. There is no effective vaccine available for preventing the disease. Survivors from clinical disease generally become carriers of ASF virus (ASFV) for life [30, 32]. Carriers and chronically infected pigs usually acquire and die from ASF specific necotizing pneumonia $[10-14,16,29]$, accompanied by hypergammaglobulinemia $[15,22]$, and sera from pigs recovered from clinical disease lacks convincing neutralizing activity in vitro $[4,6]$ though they are generally refractory to homologous challenge with virulent virus $[8,21]$.

In the previous communications, we as well as others found that ASFV, including field isolates and cell adapted viruses, consisted of subpopulations of virus which differed from each other in terms of presence or absence of cetain epitopes [5, 23], genomic structures [31, 33, 34], virulence [20, 21], hemadsorption characteristics $[3,9,20,21,25,26$, $28]$, and plaque size [21, 24].

In this study, cell culture passage was used for generating subpopulations, and pigs were used for analysing the biological characteristics of the new virus populations produced.

\footnotetext{
* Present address: Dr. Pan, I. C., 376 Chung-Cheng Rd. Research Institute for Animal Health, Tansui, Taiwan, Republic of China.
}

Experiments were designed specifically to answer the following questions: (a) Does a virus population isolated from an early stage of infection differ immunogenically from that of the population isolated later from the same individual? (b) Does attenuation always occur uniformly in the newly generated subpopulations? (c) Do the major population in the parent and progenies of subsequent passages always retain its characteristics in relation to virulence, immunogenicity, and infectivity?

\section{MATERIALS AND METHODS}

Tengani $(T G)$ isolate: TG virus was isolated in Malawi [8] and is highly infectious and highly virulent (Table 1). A stock virus was prepared from a pig inoculated with virus previously passaged twice in pigs [20].

Lisbon 60 (L'60) isolate: A highly infectious and highly virulent L'60 virus was isolated from an epidemic in Portugal in 1960, and a stock virus was prepared from a pig inoculated with virus previously passaged six times in pigs [20].

Cell culture passaged TG viruses: All cell passaged TG viruses used in the experiments were originated from the TG isolate with varying cell passage histories and biological characteristics, respectively. 
Table 1. Parameters for infectivity. virulence, and class of viruses

\begin{tabular}{|c|c|c|c|c|}
\hline \multicolumn{5}{|c|}{ Parameters } \\
\hline Virus & $\mathrm{HAD}_{50} / \mathrm{PID}_{50}$ & $\mathrm{HAD}_{50} / \mathrm{LD}_{50}$ & $\mathrm{PID}_{50} / \mathrm{LD}_{50}$ & Class \\
\hline TG isolate & 0.4 & 0.4 & 1.0 & $\mathrm{HI} \& \mathrm{HV}$ \\
\hline L'60 isolate & 2.6 & 2.6 & 1.0 & $\mathrm{HI} \& \mathrm{HV}$ \\
\hline TG-LD2-BC11-VR5 & $\leq 0.9$ & $\leq 0.9$ & 1.0 & $\mathrm{HI} \& \mathrm{HV}$ \\
\hline TG-LD2-BC11-VR27 & 46.5 & $\geq 4,652.0$ & $\geq 100.0$ & MI \& SV \\
\hline \multicolumn{5}{|l|}{ ET8508 ${ }^{\text {a) }}$} \\
\hline-3 DPI blood & $\leq 1.2$ & NT & NT & $\mathrm{HI} \& \mathrm{SV}$ \\
\hline-6 DPI blood & $\leq 11.6$ & $\geq 115,500.0$ & $\geq 10,000.0$ & $\mathrm{HI} \& \mathrm{SV}$ \\
\hline-10 DPI blood & 3.2 & 3.2 & 1.0 & $\mathrm{HI} \& \mathrm{HV}$ \\
\hline \multicolumn{5}{|c|}{ TG-ET287-VR7-05111 clone } \\
\hline$-V R 7$ & 1.8 & $\geq 316,227.8$ & $\geq 175,682.1$ & HI \& SV \\
\hline$-V R 23$ & 50.1 & $\geq 501,187.2$ & $\geq 100,000 . \dot{0}$ & MI \& SV \\
\hline -VR23-ET8183 ${ }^{\mathrm{b})}$ & $\leq 1.5$ & 14.6 & $\geq 10.0$ & $\mathrm{HI} \& \mathrm{MV}$ \\
\hline
\end{tabular}

a) A pig (ET8508) was inoculated with TG-VR27 virus, and blood samples were obtained 3, 6, and 10 DPI, respectively.

b) A pig (ET8183) was inoculated with TG-ET287-VR7-05111-VR23 virus, and a blood sample was obtained 10 DPI for testing in pigs.

HI or MI: Highly or moderately infectious.

HV, MV or SV: Highly, moderately or slightly virulent.

NT: Not tested.

$\mathrm{HAD}_{50} / \mathrm{PID}_{50}: 50 \%$ hemadsorption unit(s) required to induce one $50 \%$ pig infectious unit.

$\mathrm{HAD}_{50} / \mathrm{LD}_{50}: 50 \%$ hemadsorption unit(s) required to induce one $50 \%$ pig lethal unit.

$\mathrm{PID}_{50} / \mathrm{LD}_{50}: 50 \%$ pig infectious unit(s) required to induce one $50 \%$ pig lethal unit.

All infected cells were cultured at $33^{\circ} \mathrm{C}$ and $3 \% \mathrm{CO}_{2}$ [22]. Each virus was named by the respective virus passage history, either in cell cultures or in pigs, in a sequential manner. For an example, the virus named TG-LD2-BC11-VR5 is read as follows: TG isolate was passaged twice in buffy coat cell cultures (BC) with limitting dilution technique (TG-LD2), followed by eleven blind passages in BC (TG-LD2$\mathrm{BC} 11)$ and five blind passages in Vero cell cultures (TG-LD2-BC11-VR5), respectively. The method of virus adaptation in $\mathrm{BC}$ and Vero cells was described previously [22]. Thus, TG-LD2-BC11-VR5 (TGVR5) was further passaged 10 and 22 times in Vero cells (TG-VR15 and TG-VR27 viruses), and viruses were tested in pigs, respectively.

Cloned TG viruses: A pig (ET287) was made solidly immune to L'60 isolate [21] and was challenge inoculated with TG isolate to obtain the virus populations intrinsic to TG isolate. The pig died from acute ASF, and virus was isolated from the spleen of the carcass (TG-ET287). The virus was adapted to Vero cells by seven blind passages in Vero cell cultures (TG-ET287-VR7). A virus clone (TG-ET287-VR7-05111) was obtained by four cycles of plaque purification procedure [23] and further blindly passaged seven and twenty three times in Vero cell cultures (TG-ET287-VR7-05111VR7 and - VR23), respectively.
Titrations of virus and antibody: Heparinized blood or organ suspensions were sonicated, decimally diluted, and titrated in $\mathrm{BC}$, and the virus titer was expressed as $50 \%$ hemadsorption unit(s) per $\mathrm{m} l$ $\left(\mathrm{HAD}_{50} / \mathrm{ml}\right)$; and the virus infectivity was titrated in pigs and expressed as numbers of $\mathrm{HAD}_{50}$ required to induce one $50 \%$ pig infectious unit $\left(\mathrm{HAD}_{50} /\right.$ $\mathrm{PID}_{50}$ ) as described previously [20]. Since avirulent virus does not replicate in vivo [20], the percentage of an avirulent population in a virus preparation when present as a major population was calculated as follows:

$$
\left(1-\frac{\text { Numbers of } \mathrm{HAD}_{50} / \mathrm{PID}_{50}}{\text { Total } \mathrm{HAD}_{50} \text { of Virus Preparation }}\right) \times 100
$$

[20]. Antibody was titrated by the indirect immunoperoxidase plaque staining (IIPS) test [19].

Parameters for expressing virulence and infectivity: The virulence and infectivity of an ASF virus isolant were expressed as previously described [20]. A low $\mathrm{HAD}_{50}$ requirement for either $\mathrm{PID}_{50}$ or $50 \%$ lethal dose $\left(\mathrm{LD}_{50}\right)$, i.e., $\leq 10.0$, was indicative of high virulence or high infectivity, respectively, and a low $\mathrm{PID}_{50}$ requirement to attain one $\mathrm{LD}_{50}$, i.e., $\leq 1.0$, was indicative of highly infectious and highly virulent nature of the virus. Higher ratios were indicative of lesser virulence or infectivity. 
RESULTS

\section{TG-LD2-BC11 Virus}

Highly virulent nature of TG-VR5 virus: Two groups of two pigs each, housed in individual dog cages, were inoculated, I. M., with 18 and 1.8 $\mathrm{HAD}_{50}$ units of the virus, respectively. Pyrexia started 3 days post-inoculation (DPI) and held at between 40.0 to $41.7^{\circ} \mathrm{C}$ until all of the pigs died by 8 DPI from acute ASF. Thus, the virus is classified as highly infectious and highly virulent (Table 1).

Dominance of moderately virulent virus in $T G$ VR15: The TG-VR15 virus was serially diluted in 10 -fold increments, and each dilution of virus was inoculated into a 3-day-old BC. After 6 days of incubation, extensive hemadsorption and cytopathic effects were observed. Virus harvests identified according to the dilution of the inoculum used to infect the culture was titrated individually in BC. Each virus harvest was adjusted to $100 \mathrm{HAD}_{50} / \mathrm{m} l$ and then used to inoculate pigs. Four groups of two pigs each in respective pig pens were inoculated with $100 \mathrm{HAD}_{50}$ of respective virus harvests (Table 2).

The pigs responded with different clinical courses. All pigs which were inoculated with the virus prepared from the $\mathrm{BC}$ infected with $10^{-4.0}$ to $10^{-6.0}$ dilutions of TG-VR15 virus either died from acute or peracute ASF by 10 DPI. On the other hand, two pigs inoculated with $10^{-7.0}$ virus dilution developed subacute ASF. Thus, TG-VR15 virus appeared to contain at least two distinctly different subpopulations in terms of virulence, i.e., the dominant population of at least $90 \%$ was moderately virulent virus and the other (less than 10\%) was highly virulent.

Less virulence and less contagious nature of

Table 2. Mixed virus populations in TG-LD2-BC11-VR15 virus

\begin{tabular}{ccccl}
\hline ET No. & $\begin{array}{c}\text { Dilution } \\
\text { Inoculum }\end{array}$ & $\begin{array}{c}\text { Dosage } \\
\left(\mathrm{HAD}_{50}\right)\end{array}$ & \multicolumn{1}{c}{ Fate } & Clinical Course \\
\hline 8224 & $10^{-40}$ & 100 & Died 7 DPI & Peracute ASF \\
8223 & $10^{-40}$ & 100 & Died 7 DPI & Peracute ASF \\
8222 & $10^{-5.0}$ & 100 & Died 7 DPI & Peracute ASF \\
8219 & $10^{-5.0}$ & 100 & Died 10 DPI & Acute ASF \\
8218 & $10^{-6.0}$ & 100 & Died 9 DPI & Acute ASF \\
8216 & $10^{-60}$ & 100 & Died 7 DPI & Peracute ASF \\
8214 & $10^{-70}$ & 100 & Died 10 DPI & Subacute ASF \\
8194 & $10^{-70}$ & 100 & $\begin{array}{c}\text { Killed, moribund } \\
\text { stage, 14 DPI }\end{array}$ & Subacute ASF \\
& & &
\end{tabular}

a) Serial-ten fold dilutions of TG-VR15 virus were used to infect buffy coat cell cultures, respectively. The virus preparations harvested were each adjusted to $100 \mathrm{HAD}_{50} / \mathrm{m} l$ before pig inoculation.

Table 3. Avirulent population as the major constituent and less contagious nature of TG-LD2-BC11-VR27 virus

\begin{tabular}{|c|c|c|c|c|c|c|c|}
\hline \multirow[t]{2}{*}{ ET No } & \multirow[t]{2}{*}{ Dilution } & \multirow[t]{2}{*}{$\begin{array}{l}\text { Dosage } \\
\left(\mathrm{HAD}_{50}\right)\end{array}$} & \multirow[t]{2}{*}{ Fate } & \multicolumn{3}{|c|}{$\begin{array}{c}\text { Viremia Titer } \\
\left(\log _{10} \mathrm{HAD}_{50} / \mathrm{m} l \text { blood }\right)\end{array}$} & $\begin{array}{l}\text { Antibody } \\
\text { Titer }\end{array}$ \\
\hline & & & & 3 DPI & $6 \mathrm{DPI}$ & $10 \mathrm{DPI}$ & $10 \mathrm{DPI}$ \\
\hline 8508 & $10^{-30}$ & $1,470.0$ & $\mathrm{D}^{12}(\mathrm{SA})$ & 1.3 & 6.3 & 6.8 & $1: 100$ \\
\hline 8507 & $10^{-30}$ & $1,450.0$ & $\mathrm{~K}^{10}(\mathrm{SA})$ & NT & 7.2 & 7.8 & $1: 100$ \\
\hline 8512 & $10^{-40}$ & 147.0 & $\mathrm{D}^{20}(\mathrm{SA})$ & NT & 6.7 & 5.6 & $1: 10$ \\
\hline 8513 & $10^{-40}$ & 147.0 & $\mathrm{D}^{12}(\mathrm{SA})$ & NT & 6.5 & 6.5 & Neg \\
\hline 8514 & $10^{-5.0}$ & 14.7 & $\mathrm{D}^{21}(\mathrm{SA})$ & NT & $\mathrm{Neg}$ & Neg & Neg \\
\hline 8515 & $10^{-50}$ & 14.7 & $\mathrm{D}^{21}(\mathrm{SA})$ & NT & $\mathrm{Neg}$ & Neg & $\mathrm{Neg}$ \\
\hline 8519 & Contact & infection & $\mathrm{K}^{25}(\mathrm{SA})$ & Neg & Neg & Neg & Neg \\
\hline 8527 & Contact & infection & $\mathrm{K}^{22}(\mathrm{SA})$ & Neg & Neg & Neg & Neg \\
\hline
\end{tabular}

Note: All pigs were on the floor and mixed together during a 25-day observation period. Both contact pigs were sacrificed at moribund stage.

a) Reciprocal of the highest dilution of serum which had positive reaction. SA: Clinical signs and lesions of subacute ASF. D ${ }^{12}$ : Died 12 DPI. K ${ }^{10}$ : Killed at moribund stage 10 DPI. NT: Not tested. Neg: Negative. 
TG-VR27: Three groups of 2 pigs each were inoculated I.M. with various $\mathrm{HAD}_{50}$ of virus, respectively, and two contact controls were housed together with inoculated pigs on the floor during a 25-day observation period (Table 3 ).

The virus had reduced in virulence considerably through 27 passages in Vero cell cultures, i.e., the minimum $\mathrm{HAD}_{50}$ needed for inducing an acute death in a pig by TG-VR27 virus $\left(\mathrm{HAD}_{50} / \mathrm{LD}_{50}\right.$ 24,652 ) was at least 5,000 times that needed to achieve the same for the parent virus $\left(\mathrm{HAD}_{50} / \mathrm{LD}_{50}\right.$ $\leq 0.9$ ). On the other hand, $\mathrm{HAD}_{50}$ required for one unit of PID $_{50}$ increased by only about 116 times, i.e., the virulence of 27 th passage virus dropped significantly, yet the infectivity decreased to a moderate

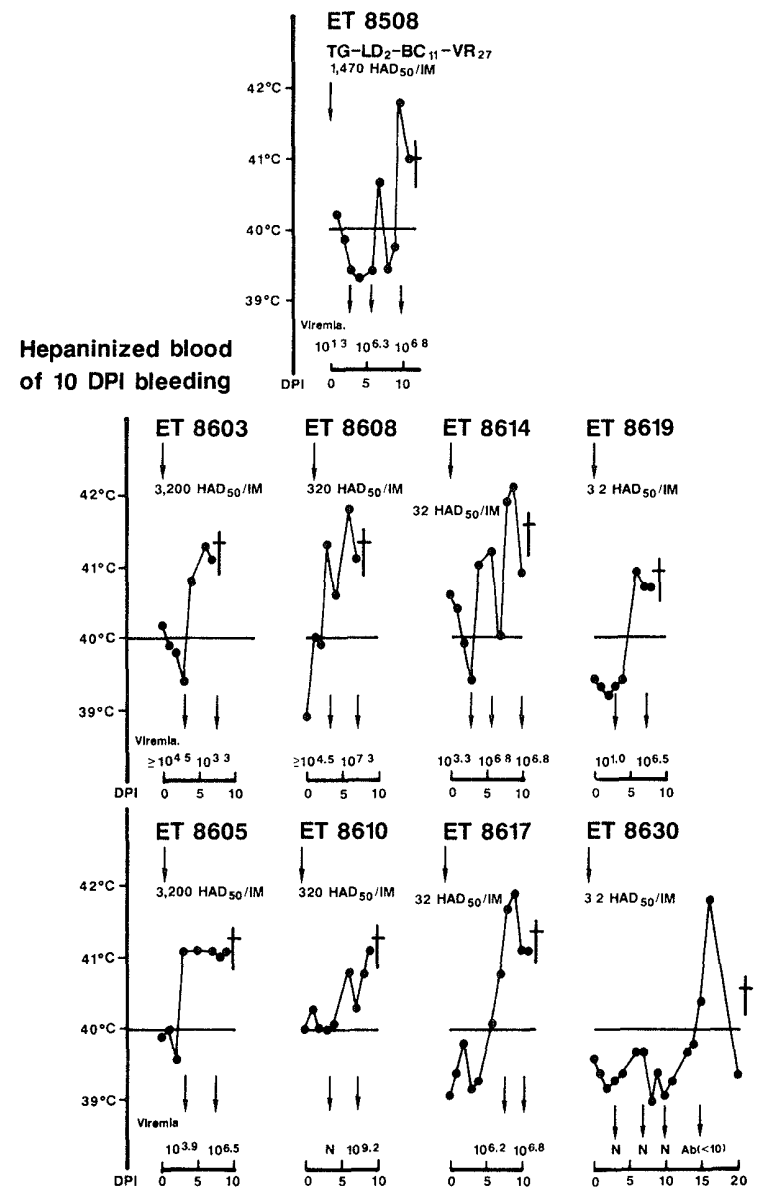

Fig. 1. A pig (8508) was inoculated with $1,470 \mathrm{HAD}$ of TG-LD2-BC11-VR27 virus, I.M. A sample of viremic blood was drawn $10 \mathrm{DPI}$ and was appropriately diluted to contain $3,200,320,32$ and $3.2 \mathrm{HAD}_{50} / \mathrm{m} l$ of virus. Four groups of two pigs each were inoculated with respective dilutions of the inoculum, I.M. All pigs, except the one received the least quantity of virus (ET8630), died from acute ASF. N: Negative viremia. $\dagger$ : Died. $\$$ : Euthanized. degree (Table 3).

It was of interest that two pigs (ET8514, ET8515) inoculated with the lowest dosage $\left(14.7 \mathrm{HAD}_{50}\right)$ and two contact controls were not viremic nor was antibody demonstrable 10 DPI, i.e., the virus population inoculated did not replicate in pigs (avirulent) nor did two contact pigs contract ASF during this period (least contagious). Thus, TGVR27 virus appeared to be moderately infectious and slightly virulent. Furthermore, $99 \%$ of virus population was avirulent (Table 1).

Virulence and immunogenicity of viremic blood: A pig (ET8508) in the previous experiment (Table 3) had a diphasic pyrexia within a 12-day clinical course in response to an inoculation of TG-VR27 virus (Fig. 1). Viremia was demonstrated in the blood samples collected 3 and 6 DPI, respectively, during the asymptomatic period, and at 10 DPI when its body temperature was at its second peak. The differences in virulence and immunogenicity of virus populations contained in the respective viremic blood samples were assessed by inoculating susceptible pigs as follows.

Highly virulent nature of blood collected 10 DPI: Eight pigs were housed in four pens with two pigs per pen. Two pigs in each group were inoculated with ten-fold serial dilutions of the blood containing $3,200,320,32$, and $3.2 \mathrm{HAD}_{50}$ of the virus, respectively (Fig. 1).

Seven inoculated pigs died from acute ASF; and the remaining one (ET8630) contracted the disease from the other one in the same pen (ET8619) and died from acute ASF at 20 DPI. Thus, the virus in the 10 DPI blood was highly infectious and highly virulent, i.e., only $3.2 \mathrm{HAD}_{50}$ were required to attain $1 \mathrm{PID}_{50}$ and $1 \mathrm{LD}_{50}$, respectively. The data also indicated that the virulent virus was the major population in the viremic blood of 10 DPI. Therefore, a highly infectious and highly virulent virus population was present in TG-VR27 virus, that is itself appeared as a moderately infectious and slightly virulent virus (Table 1).

Low virulence and mismatched immunogenicity of 3 DPI blood: The blood collected 3 DPI was of very low viremia titer (101.3 $\mathrm{HAD}_{50} / \mathrm{m} l$ blood). Infectivity of $\leq 1.2 \mathrm{HAD}_{50} / \mathrm{PID}_{50}$ was obtained; however, virulence could not be titrated due to its low viremic titer. Therefore, the blood was diluted to $1: 10\left(2.1 \mathrm{HAD}_{50} / \mathrm{m} l\right)$ and was inoculated to 6 pigs, $1 \mathrm{ml}$, I.M., respectively. Two uninoculated pigs were placed together with the inoculated pigs to 

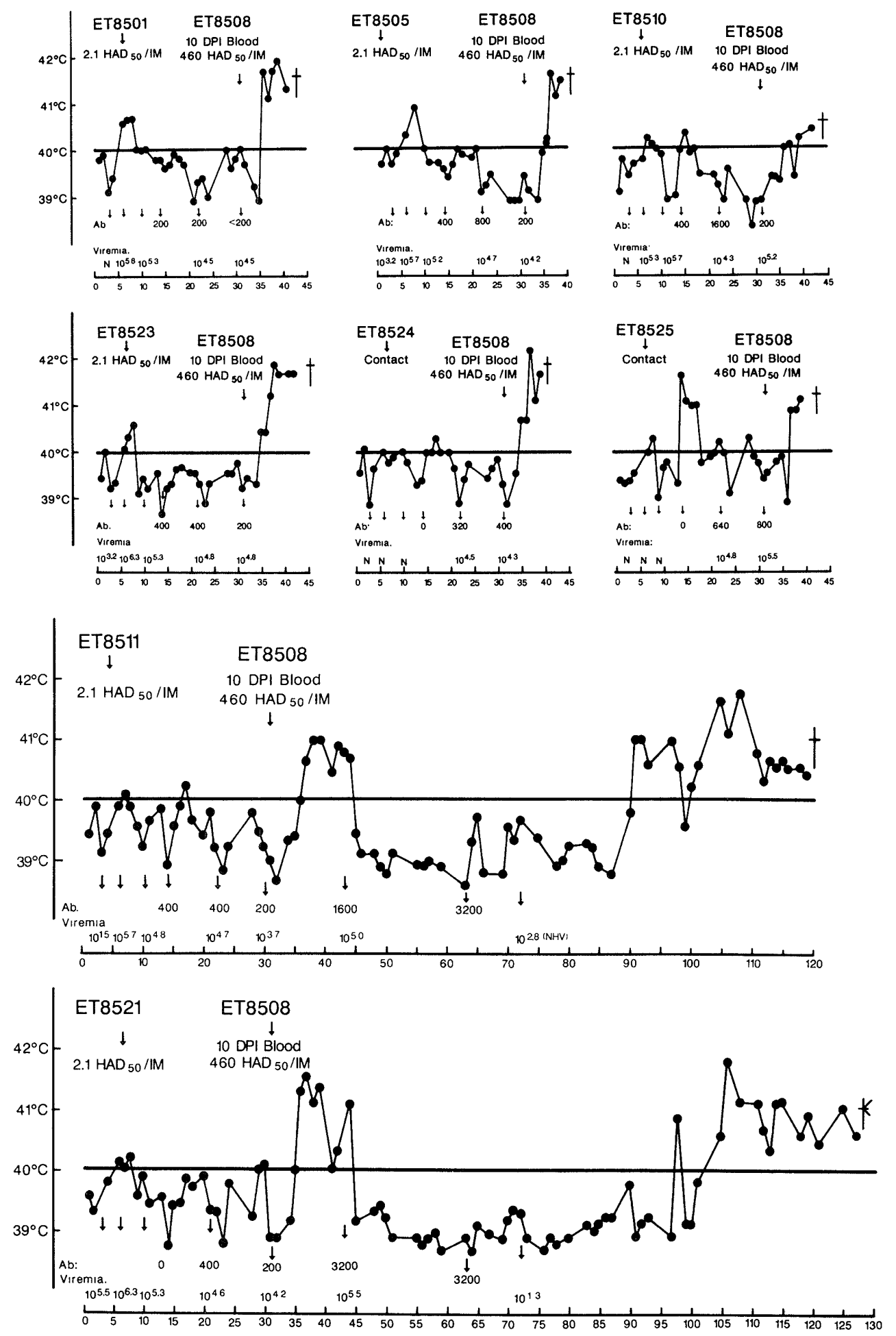

Fig. 2. Heparinized blood drawn 3 DPI from pig ET 8508, which had been inoculated with TG-LD2-BC11-VR27 virus, was diluted $1: 10$, and $1 \mathrm{ml}$ each of diluted blood containing $2.1 \mathrm{HAD}_{50}$ of virus was inoculated to 6 pigs, I.M. Two uninoculated pigs (ET8524, 8525) were mixed with other pigs on the floor for monitoring transmission of virus. All pigs recovered clinically from two to three days of low grade fever. All pigs were challenge inoculated with $460 \mathrm{HAD}\left(146 \mathrm{LD}_{50}\right)$ of virus at $30 \mathrm{DPI}$ in a form of diluted $10 \mathrm{DPI}$ blood from the same donor pig (ET8508). Six pigs, including two contacts, died from acute ASF, and the remaining two (ET8511 and 8521) developed diphasic fever and ASF pneumonia. One died $90 \mathrm{DPC}$ and the other euthanized at the moribund stage $97 \mathrm{DPC}$. NHD: Non-hemadsorbing virus. $t$ : Died. $*$ : Euthanized. 
Table 4. Virulence and immunogenicity of virus in 6 DPI blood of ET8508, exposed to TG-LD2-BC11-VR27 virus

\begin{tabular}{|c|c|c|c|c|c|}
\hline ET No. & $\begin{array}{c}\text { Dosage } \\
\left(\mathrm{HAD}_{50}\right)\end{array}$ & Fate & $\begin{array}{c}\text { Challenge with } \\
\text { Dosage }\end{array}$ & $\begin{array}{l}10 \text { DPI Blood } \\
\text { Fate }\end{array}$ & $\begin{array}{c}\text { Challenge }^{\mathrm{d})} \text { with } \\
\text { TG Isolate }\end{array}$ \\
\hline 8592 & 21,000 & Rec. 22 DPI & $10 \mathrm{HAD}$ & Rec. 47 DPC & Solidly Immune \\
\hline 8604 & 21,000 & Rec. 55 DPI & 10 HAD & Rec. 27 DPC & Solidly Immune \\
\hline 8620 & 2,100 & Died, $43 \mathrm{DPI}^{\mathrm{a})}$ & NT & - & NT \\
\hline 8622 & 2,100 & Rec. 34 DPI & $10 \mathrm{HAD}$ & Rec. 27 DPC & Solidly Immune \\
\hline 8627 & 210 & Rec. 41 DPI & $10 \mathrm{HAD}$ & Died, $45 \mathrm{DPC}^{\mathrm{b})}$ & NT \\
\hline 8628 & 210 & Rec. 41 DPI & $10 \mathrm{HAD}$ & Rec. 15 DPC & Solidly Immune \\
\hline 8629 & 21 & Rec. 31 DPI & 10 HAD & Died, $\left.88 \mathrm{DPC}^{\mathrm{b}}\right)$ & NT \\
\hline 8631 & 21 & Rec. 29 DPI & 10 HAD & Died, $13 \mathrm{DPC}^{\mathrm{c})}$ & NT \\
\hline
\end{tabular}

a) Died from a diffuse, hemorrhagic, necrotizing ilitis, unrelated to ASF.

b) Died from extensive ASF pneumonia.

c) Died from subacute ASF.

d) Challenge inoculated 120 DPI with 4,600 $\mathrm{HAD}_{50}\left(11,500 \mathrm{LD}_{50}\right)$ of TG isolate. Solidly Immune: Refractory to challenge inoculation without clinical signs, viremia or increase in antibody titers. DPI: Days-post inoculation.

DPC: Days-post challenge.

Rec.: Recovered from clinical signs of ASF.

observe transmission of the virus by direct contact.

All inoculated pigs had 1 to 4 days of pyrexia and relatively high titered viremia within 10 DPI (Fig. 2). All pigs including two contacts were clinically normal, but were viremic and had relatively low antibody titers, when they were challenge inoculated with 10 DPI blood of ET8508 $\left(146 \mathrm{LD}_{50}\right), 30$ DPI (Fig. 2).

Four inoculated pigs and two controls died from acute ASF after challenge inoculation. The remaining two became chronic infection and acquired ASF pneumonia; one died $120 \mathrm{DPI}$, and the other was killed at the moribund stage 127 DPI (Fig. 2).

Low virulence and immunogenicity of virus in 6 DPI blood: Blood collected 6 DPI was serially diluted in 10 fold increments from $10^{-2.0}$ to $10^{-5.0}$, and two pigs each were inoculated with respective dilutions of the virus (Table 4). All pigs had relatively high viremic titers averaging $10^{4.4} \mathrm{HAD}_{50} /$ $\mathrm{m} l$ blood by 37 DPI, and seven of eight pigs recovered from moderate clinical signs of ASF within 55 DPI. Viremia was no longer demonstrable in any of the remaining seven pigs by 63 DPI. The other pig died from a necrotizing enteritis, unrelated to ASF.

All pigs had 1:1,250 or higher antibody titers 63 DPI when they were challenge inoculated I.M. with 3.1 $\mathrm{LD}_{50}$ units of virus in diluted 10 DPI blood. Three pigs died from subacute ASF (Table 4). The remaining 4 pigs recovered from mild clinical signs of ASF, 47 days post challenge (DPC), and they were further challenge inoculated with $11,500 \mathrm{LD}_{50}$ units of virulent TG isolate, I.M. All pigs were clinically normal during a 48-day observation period; however, they all had acquired a chronic ASF pneumonia by the time they were euthenized and necropsied at 184 DPI.

\section{TG-ET287-VR7-05111 (TG-05111) Virus Clone}

Virulence of TG-05111-VR7: Eight pigs were housed in individual dog cages, and two pigs each were inoculated I.M. with a serial 10 -fold dilution of the virus.

Six pigs died from subacute ASF with a presence of antibody and the other two recovered clinically with high antibody titers (Table 5). From another experiment, infectivity of $1.8 \mathrm{HAD}_{50} / \mathrm{PID}_{50}$ was obtained (data not shown). Thus, TG-05111-VR7 was a highly infectious and slightly virulent virus (Table 1).

Virulence, immunogenicity and infectivity of TG05111-VR23: Eight pigs were inoculated with a serial 10 -fold dilution of $23 \mathrm{rd}$ passage virus, and were housed together on the floor (Table 6).

Seven pigs recovered from mild clinical signs of ASF by 53 DPI. The eighth pig was accidentally killed at the time of bleeding 14 DPI. All but one had viremia between 5 and 26 DPI. Viremia could not be detected in a pig (ET8623), which had received virus at the highest dilution, but presence of antibody was detected at 14 and 26 DPI, respectively (Table 7 ). It indicated that virus replication had occurred in vivo without detectable viremia nor clinical signs of ASF (Table 6). Therefore, the virus was considered to be moderately infectious and slightly virulent (Table 1 ) with more than $99.9 \%$ 
Table 5. Virulence and infectivity of TG-05111-VR7 virus in pigs

\begin{tabular}{|c|c|c|c|c|c|}
\hline ET No. & $\begin{array}{c}\text { Dosage } \\
\log _{10} \mathrm{HAD}_{50}\end{array}$ & Fate & Virus & $\operatorname{ter}^{b)}$ & Antibody Titer ${ }^{c)}$ \\
\hline 4233 & 5.0 & Died, 10 DPI, SA ASF & Spleen & $\leq 4.5$ & 1: 1,000 \\
\hline 4232 & 5.0 & Clinically Recovered & Blood & 3.6 & 1: 10,000 \\
\hline 4231 & 4.0 & Died, 11 DPI, SA ASF & Spleen & 6.3 & 1: 10 \\
\hline 4230 & 4.0 & Died, 12 DPI, SA ASF & Spleen & 5.0 & 1: 100 \\
\hline 4229 & 3.0 & Died, 11 DPI, SA ASF & Spleen & 5.8 & $1: \geq 1,000$ \\
\hline 4227 & 3.0 & Died, 12 DPI, SA ASF & Spleen & 7.3 & 1: 100 \\
\hline 4225 & 2.0 & Clinically Recovered & Blood & 3.0 & 1: 10,000 \\
\hline 4224 & 2.0 & Died, 12 DPI, SA ASF & Spleen & 2.8 & 1: 1,000 \\
\hline
\end{tabular}

a) The total virus infectivity of this virus preparation was $10^{7.0} \mathrm{HAD}_{50} / \mathrm{m} l$.

b) $\log _{10}$ virus titer/g of spleen, or $/ \mathrm{m} l$ of defibrinated blood collected at necropsy, 26 DPI.

c) Antibody titer of blood collected from portal vein of carcass or blood from anterior vena cava of clinically recovering pigs (ET4232, 4225), 26 DPI. SA ASF: Subacute ASF.

Table 6. Virulence and viremia titrations of TG-05111-VR23 virus

\begin{tabular}{|c|c|c|c|c|c|c|c|}
\hline \multirow[b]{2}{*}{ ET No. } & \multirow{2}{*}{$\begin{array}{l}\text { Inoculum }^{\text {a) }} \\
\log _{10} \mathrm{HAD}_{50}\end{array}$} & \multicolumn{5}{|c|}{ Viremia Titer $\left(\log _{10} \mathrm{HAD}_{50} / \mathrm{m} l\right.$ blood $)$} & \multirow[b]{2}{*}{ Fate } \\
\hline & & $5 \mathrm{DPI}$ & 7 DPI & 14 DPI & $26 \mathrm{DPI}$ & 53 DPI & \\
\hline 8593 & 5.2 & 4.5 & 3.8 & 3.8 & 2.2 & Neg & $\operatorname{Rec}$ \\
\hline 8594 & 5.2 & 3.7 & 3.5 & 3.2 & 2.2 & $\mathrm{Neg}$ & $\operatorname{Rec}$ \\
\hline 8599 & 4.2 & 4.5 & 2.5 & 2.8 & 1.8 & $\mathrm{Neg}$ & $\operatorname{Rec}$ \\
\hline 8601 & 4.2 & 3.7 & 3.3 & 3.2 & 0.8 & Neg & $\operatorname{Rec}$ \\
\hline 8606 & 3.2 & 3.5 & 2.3 & 2.5 & 0.7 & $\mathrm{Neg}$ & $\operatorname{Rec}$ \\
\hline 8613 & 3.2 & 4.2 & 4.8 & 4.2 & NT & NT & $\mathrm{K} 14^{\mathrm{c})}$ \\
\hline 8621 & 2.2 & Neg & 3.8 & 3.5 & 2.0 & Neg & $\operatorname{Rec}$ \\
\hline 8623 & 2.2 & $\mathrm{Neg}$ & Neg & $\mathrm{Neg}^{\mathrm{b})}$ & $\mathrm{Neg}^{\mathrm{b})}$ & $\mathrm{Neg}$ & $\operatorname{Rec}$ \\
\hline
\end{tabular}

a) Virus titer of undiluted virus preparation was $10^{70} \mathrm{HAD}_{50} / \mathrm{m} l$.

b) Antibody titers of 1:25 and 1: 6,250 for sera collected 14 and 26 DPI, respectively.

c) Accidental death during bleeding 14 DPI, when the pig appeared clinically normal. NT: Not tested.

Neg: Negative.

Table 7. Antibody titers of sera collected from pigs exposed to TG-05111-VR23 virus and fate of pigs to challenge inoculations

\begin{tabular}{|c|c|c|c|c|c|c|c|c|}
\hline \multirow[b]{2}{*}{ ET No. } & \multicolumn{6}{|c|}{ Days Post Exposure } & \multicolumn{2}{|c|}{ Response to } \\
\hline & 14 & 26 & $53^{a)}$ & 83 & 133 & $164^{b)}$ & TG & L'60 \\
\hline & & & Antibod & y Titer & & & & \\
\hline 8593 & 5 & 250 & 6,250 & 31,250 & $>156,250$ & 6,250 & 1 & 1 \\
\hline 8594 & 25 & 250 & 6,250 & 31,250 & 31,250 & 31,250 & 1 & 1 \\
\hline 8599 & $<5$ & 1,250 & 31,250 & 156,250 & 31,250 & NT & 1 & 0 \\
\hline 8601 & $<5$ & 1,250 & $>156,250$ & 31,250 & NT & NT & 0 & NT \\
\hline 8606 & 25 & 1,250 & 6,250 & 31,250 & $>156,250$ & 31,250 & 1 & 2 \\
\hline 8613 & 25 & NT & NT & NT & NT & NT & NT & NT \\
\hline 8621 & 25 & 1,250 & 31,250 & 156,250 & 31,250 & 31,250 & 1 & 3 \\
\hline 8623 & 25 & 6,250 & 1,250 & NT & NT & NT & 0 & NT \\
\hline
\end{tabular}

Note: Antibody titers were the reciprocal of the highest dilution of serum which had positive reaction.

a) Challenge inoculated with $10^{4.5} \mathrm{HAD}_{50}\left(10^{4.5} \mathrm{LD}_{50}\right)$ units of $\mathrm{TG}$ isolate, I.M.

b) Challenge inoculated with $10^{4.2} \operatorname{HAD}_{50}\left(10^{3.8} \mathrm{LD}_{50}\right)$ units of L'60 isolate, I.M.

c) Each numerical reflects different clinical responses as follows:

3 , solidly immune to challenge without clinical signs, viremia, nor increse in antibody titers 2 , one day pyrexia, may or may not increased antibody titer and clinically recovered; 1 , more than one day pyrexia, increase in antibody titer and clinically recovered: 0 , died from ASF. 

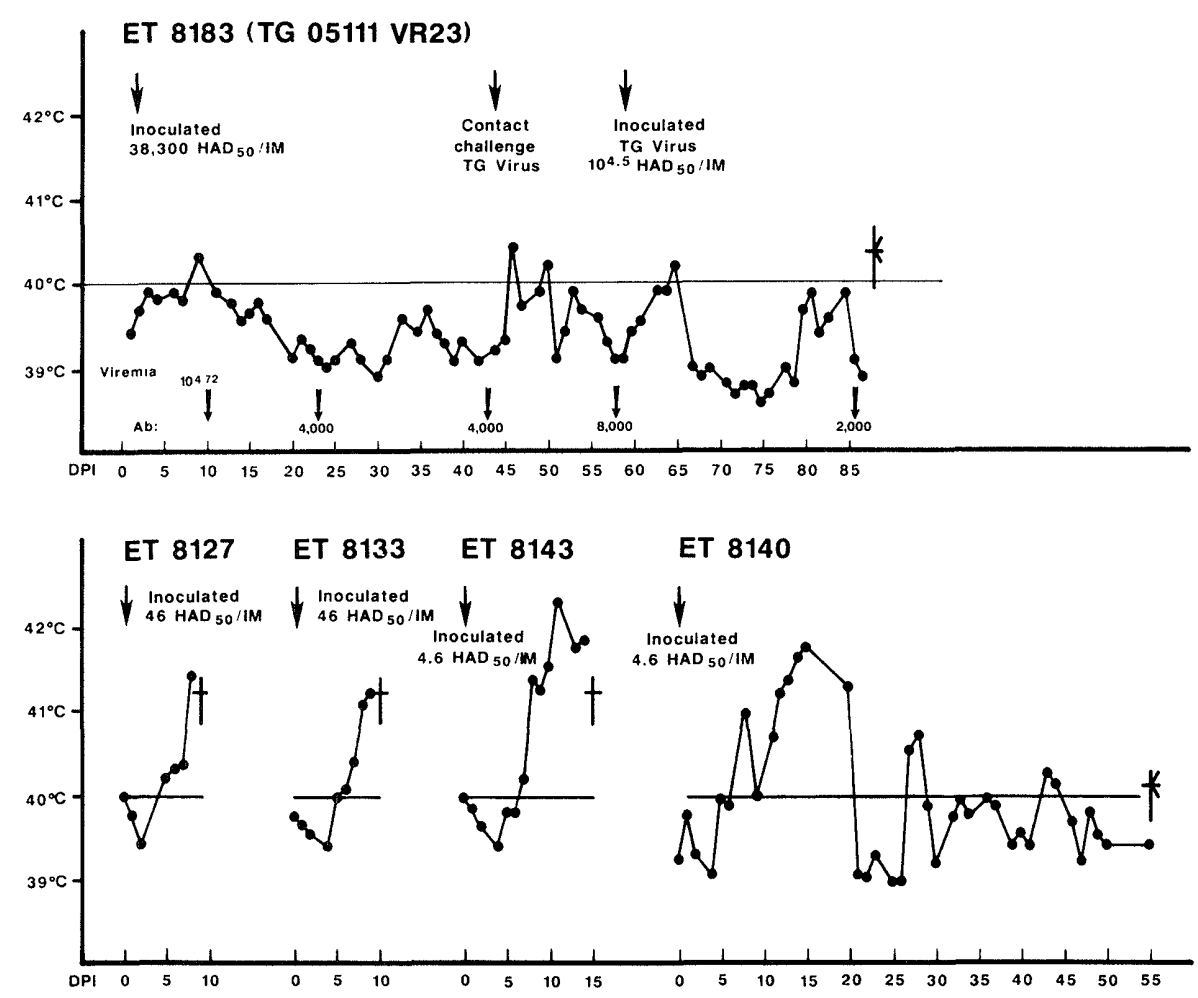

Fig. 3. Pig ET8183 was inoculated with $38,300 \mathrm{HAD}_{50}$ of TG-05111-VR23 virus which was moderately infectious and slightly virulent. A spike of fever $\left(40.6^{\circ} \mathrm{C}\right)$ was observed $9 \mathrm{DPI}$, and a heparinized blood sample was collected 10 DPI. Subsequently, the pig was clinically normal and was refractory to a homologous challenge with TG isolate later. Two pigs (ET8127, 8133) which received $46 \mathrm{HAD}_{50}$ of virus in $10 \mathrm{DPI}$ blood of pig ET8183 died from acute ASF. One of two pigs which received 4.6 $\mathrm{HAD}_{50}$ of virus, pig ET8143 died from subacute ASF and the other (ET8140) survived the clinical disease. $f$ : Euthanized.

of its total population consisting of virus capable of causing subclinical infection and possibly associated with an avirulent population of undetermined proportion.

When they were free from viremia (53 DPI), all seven pigs were challenge inoculated with the TG isolate. Five pigs survived and returned to normal clinically with high titers of antibody; the other two pigs died from subacute ASF and ASF pneumonia, respectively (Table 7 ).

To see whether the survivors would stand a challenge inoculation with a heterologous virus, five survivors were challenge inoculated with L'60 isolate, 133 DPI. Four pigs had one or two episodes of recurring fever of 2- to 3-day duration and were clinically normal when they were euthanized 250 DPI. At encropsy, all had chronic ASF pneumonia. The remaining one died from acute ASF (Table 7).

Virulent virus in 10 DPI blood of a pig infected with TG-05111-VR23 virus: In another experiment, a pig inoculated with $38,300 \mathrm{HAD}_{50}$ of the virus had only one spike of fever 9 DPI (Fig. 3). It resisted both contact and parenteral challenges with TG isolate with spikes of one-day fever, shortly after each challenge. Thereafter, the pig appeared clinically normal and was euthenized 87 DPI with an relatively low antibody titer of 2,000 ; and the viscera appeared normal, grossly. Attempts to isolate virus from gastric and renal lymph nodes in $\mathrm{BC}$ were negative.

The viremic blood collected 10 DPI was appropriately diluted, and two groups of two pigs each were inoculated with 46 and $4.6 \mathrm{HAD}_{50}$ of virus, respectively. The two pigs inoculated with $46 \mathrm{HAD}_{50}$ of virus died from subacute ASF. One of the two pigs inoculated with 4.6 $\mathrm{HAD}_{50}$ of virus, one died from subacute ASF, and the other survived the clinical disease (Fig. 3). Therefore, the major virus population contained in the 10 DPI viremic blood was moderately virulent which significantly differed from that of the parent, TG-05111-VR23 virus (Table 1). 


\section{DISCUSSION}

A virus clone serially passaged in cell cultures was apparently capable of generating subpopulations with varying degrees of virulence, immunogenicity and infectivity. It is certain, therefore, that subpopulations generated by uncloned virus would be even more heterogeneous, as reported in this communication, than those generated by a cloned virus.

The complexity of heterogeneous subpopulations generated by cell passages poses a critical problem in selecting proper virus preparation for an experiment, regardless of whether it be for antigen in neutralization test $[4,6]$, genome analysis $[5,31$, 33], generation of monoclonal antibodies [35, 36], epitopic analysis of virions $[5,23,36]$, or immunogen for preparing an experimental subunit vaccine, etc. Very little, if any, attention has been paid to this critical problem in ASF research in the past due to a paucity of information on the characteristics of subpopulations generated by cell passages, as reported here.

In this regard, it is important to bear in mind that more than $90 \%$ of the population in high-passage virus is often avirulent, i.e., the major population is an artefact of laboratory creation, but does not exist in nature. Because, avirulent virus does not replicate in pigs [20]. It is clear, therefore, that in working with an ASF virus that has been passaged in cell cultures, one might be using a "model system" that has no counterpart in nature. The data presented here support this thesis.

In the pigs inoculated with TG-VR27 virus, the virulence and immunogenicity of the virus populations contained in the blood at 3 DPI distinctly differed from that in 10 DPI blood (Figs. 1 and 2). It indicated that TG-VR27 virus was a mixture of subpopulations in which more than $99.9 \%$ was avirulent, and a continuous modulation of the virus population took place in the infected pig. Although the virus in 6 DPI blood was also of slight virulence, it was able to confer immunity against challenge inoculations with 10 DPI blood first and homologous, virulent TG isolate later. The episode of two sharp peaks of one-day pyrexia each in ET8508 coincided well with this "shift" in virus population (Fig. 1).

A pig (ET8183) inoculated with a massive dose of a virus clone (TG-05111-VR23) responded with a spike of one-day fever and was refractory to a challenge inoculation with homologous, highly virulent TG isolate. In addition to declining in antibody titers, there were no gross lesions suggestive of ASF nor positive virus isolation from lymph nodes. In view of these facts, the viremic blood (10 DPI) was inoculated to pigs to see whether the virus in blood consisted solely of a low virulent and immunogenic population. Contrary to expectation, the virus contained in 10 DPI blood required only $1 / 21,790$ of the $\mathrm{HAD}_{50}$ needed by the parent virus to cause a pig to die from acute ASF (Table 1). It appears that homeostasis between highly virulent and moderately virulent populations within the same preparation was keeping clinical disease in check in the infected pig.

The virus clone TG-05111 apparently altered in virulence after twenty three generations of serial passages in Vero cells by generating subpopulations of extremely low virulence that induced asymptomatic infection in pigs, which accounted for $99.9 \%$ of the total infectively measured. Contrarily, Wesley and Pan [34] reported identical genomic structure between the parent (uncloned, Vero passaged) and that prepared after twenty generations of plaque purification, indicating a highly stable nature of ASFV genome. Phenotypically, it looks contradictory to what reported here and elsewhere by others $[31,33,37]$; however, serial plaque purification for 20 generations definitely assured passage of only one major population that was present in the original, uncloned parent virus. Therefore, the possibility of carrying over the constantly arising new subpopulations of unknown frequency was almost nil.

The TG isolate contains subpopulations whose immunogenicity is not shared by L'60 and Haiti-1 isolates [21]. In this study, however, survivors from a challenge inoculation with TG isolate were generally refractory to a cross challenge inoculation with L'60 isolate. When analysed with a battery of monoclonal antibodies, raised against $14 \mathrm{~K}$ Da viral protein, the presence of a population specific to TG isolate was revealed [23]. Thus it is concluded that TG isolate contains populations of virus in which immunogenicity and antigenicity are shared by other ASFV isolated from outside of African and also contains at least one subpopulation unique to TG isolate.

The data presented here were not enough for answering questions of how subpopulations are generated and became dominant. What upsets the stability of a cloned virus? Are the apparent 
mutations random or specifically directed by the imposed conditions? The answers to these questions must await future research at molecular level.

ACKNOWLEDGEMENTS. The author thanks Mr. A. Contana for his technical help and Ms. Adriene M. Ciupryk for clerical expertise.

REFERENCES

1. Adlinger, H. K., Stone, S. S., Hess, W. R., and Bachrach, H. L. 1966. Extraction of infectious deoxyribonucleic acid from African swine fever virus. Virology 30: 750-752.

2. Breeze, S. S. Jr. and Deboer, C. J. 1967. Chemical structure of African swine fever virus investigated by electronmicroscopy. J. Gen. Virol. 1: 251-252.

3. Coggins, L. 1968. Segregation of a non-hemadsorbing African swine fever virus in tissue culture. Cornell Vet. 58: $12-20$.

4. DeBoer, C. J. 1967. Studies to determine neutralizing antibody in sera from animals recovered from African swine fever and laboratory animals inoculated with African swine fever virus with adjuvants. Arch. Virol. 20: 164-179.

5. Garcia-Barreno, B., Sanz, A., Nogal, M. L., Vinuela, E., and Enjuanes, L. 1986. Monoclonal antibodies of African swine fever virus: Antigenic differences among field isolates and viruses passaged in cell culture. J. Virol. 58: 385-392.

6. Gonzalvo, F. R., Carnero, M. E., Cabellero, C., and Martinez, M. S. 1986. Inhibition of African swine fever infection in the presence of immune sera in vivo and in vitro. Am. J. Vet. Res. 47: 1249-1252.

7. Haag, J., Larenaudie, B., and Gonzalvo, F. R. 1965. Peste porcine Africaine. Action de 1a 5-iodo-2'-deoxyuridine sur la culture du virus in vitro. Bull. Off. Int. Epizoot. 63: 717-722.

8. Hess, W. R. 1971. African swine fever virus. Virology Monographs 9: 1-33.

9. Malmquist, W. A. and Hayn, D. 1960. Hemadsorption and cytopathic effect produced by African swine fever virus in swine bone marrow and buffy coat cultures. Am. J. Vet. Res. 21: 104-108.

10. Manso Ribeiro, J., Nunes Petisca, J. L., Lopes Frazao, F., and Sobral M. 1963. Vaccination contre la peste porcine Africaine. Bull. Off. Int. Epizoot. 60: 921-937.

11. Moulton, J. and Coggins, L. 1968. Synthesis and cytopathogenesis of African swine fever virus in porcine cell cultures. Am. J. Vet. Res. 29: 219-232.

12. Moulton, J. and Coggins, L. 1968. Comparison of lesions in acute and chronic African swine fever. Cornell Vet. 58: 364-388.

13. Moulton, J., Pan, I. C., Hess, W. R., DeBoer, C. J., and Tessler, J. 1975. Pathologic features of chronic pneumonia in pigs with experimentally induced African swine fever. Am. J. Vet. Res. 36: 27-32.

14. Nunes Petisca, J. L. 1965. Etudes anatomopathologiques et histopathologiques sur la peste porcine Africaina (Virose L) au Portugal. Bull. Off. Int. Epizoot. 63: 103-142.

15. Pan, I. C., DeBoer, C. J., and Heuschele, W. P. 1970. Hypergamma-globulinemia in swine infected with African swine fever virus. Pro. Soc. Exp. Biol. Med. 134: 367-371.

16. Pan, I. C., Moulton, J., and Hess, W. R. 1975. Im- munofluorescent studies on chronic pneumonia in swine with experimentally induced African swine fever. Am. $J$. Vet. Res. 36: 379-386.

17. Pan, I. C., Shimizu, M., and Hess, W. R. 1978. African swine fever: Microplaque assay by an immunoperoxidae method. Am. J. Vet. Res. 39: 491-497.

18. Pan, I. C., Shimizu, M., and Hess, W. R. 1980. Replication of African swine fever virus in cell cultures. Am. J. Vet. Res. 41: 1357-1367.

19. Pan, I. C., Huang, T. S., and Hess, W. R. 1982. New method of antibody detection by indirect immunoperoxidase plaque staining for serodiagnosis of African swine fever. J. Clin. Microbiol. 16: 650-655.

20. Pan, I. C. and Hess, W. R. 1984. Virulence in African swine Fever: Its measurement and implications. Am. J. Vet. Res. 45: 361-366.

21. Pan, I. C. and Hess, W. R. 1985. Diversity of African swine fever virus. Am. J. Vet. Res. 46: 314-320.

22. Pan, I. C. 1987. pp. 81-126. Spontaneously susceptible cells and cell culture methodologies for African swine fever virus. In: Chapt. 8 (Becker Y. ed.), Martinus Nijhoff Publishing, Boston.

23. Pan, I. C., Whyard, T. C., Hess, W. R., Yuasa, N., and Shimizu, M. 1988. Epitopic diversity of African swine fever virus. Virus Res. 9: 93-106.

24. Parker, J. and Plowright, W. 1968. Plaque formation by African swine fever virus. Nature (Lond.) 219: 524-525.

25. Pini, A. and Magnear, G. 1974. Isolation of a nonhemadsorbing strain of African swine fever virus from a natural outbreak of the disease. Vet. Rec. 94: 2.

26. Pini, A. 1976. Isolation and segregation of nonhemadsorbing strains of African swine fever virus. Vet. Rec. 99: 479-480.

27. Plowright, W. F., Brown, F., and Parker, J. 1966. Evidence for the type of nucleic acid in African swine fever virus. Arch. Virol. 19: 283-304.

28. Sanchez Botija, C. 1962. Diagnostico differencial entra la peste porcina Africana. Symp. Int. Virol. Vet., O.I.E. A.I.S.M., Lyon. 43-50.

29. Sanchez Botija, C. 1963. Modification del virus de la peste porcina Africana en cultivos celulares. Contribucion al econocimiento de la caccion patogena y del poder de proteccion de las estirpes tenuadas. Bull. Off. Int. Epizoot. 60: 901-919.

30. Sanchez Botija, C. and Polo Jover, F. 1964. Informe sobre algunos aspectos de la peste porcina Africana en Espana en 1964. Bull. Off. Int. Epizoot. 62: 945-952.

31. Santurde, G., Gonzalvo, F. R., Canero, M. E., and Tabares, E. 1988. Genetic stability of African swine fever virus grown in monkey kidney cells. Arch. Virol. 98: $117-122$.

32. Scott, G. R. 1965. The virus of African swine fever and its transmission. Bull. Off. Int. Epizoot. 63: 645-677.

33. Tabares, E., Olivares, I., Santrude, G., Garcia, M. J., Martin, E., and Carnero, M. E. 1987. African swine fever virus DNA: Deletion and additions during adaptation to growth in monkey kidney cells. Arch. Virol. 97: 333-346.

34. Wesley, R. D. and Pan, I. C. 1982. African swine fever virus DNA: Restriction endonuclease cleavage pattern of wild type, Vero-cell adapted and plaque-purified virus. $J$. Gen. Virol. 63: 383-391. 